\title{
Hand Digit 5 Middle Phalanx
}

National Cancer Institute

\section{Source}

National Cancer Institute. Hand Digit 5 Middle Phalanx. NCI Thesaurus. Code C142300.

A long bone in the fifth finger, as counted from the thenar side of the hand; it is located between, and articulates with, the proximal and distal phalanges. 